\title{
SOLUTION TO THE ECONOMIC DISPATCH PROBLEM OF THE NIGERIAN POWER SYSTEM USING GENETIC ALGORITHM
}

\author{
S. O. Okozi ${ }^{1}{ }^{*}$, G. C. Ogbonna ${ }^{2}$, M. Olubiwe ${ }^{3}$ and E.O Ezugwu ${ }^{4}$

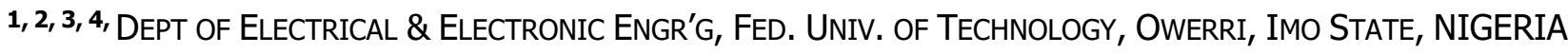 \\ Email addresses: ${ }^{1}$ samuel.okozi@futo.edu.ng, ${ }^{2}$ geraldgbnn@gmail.com, 3 olubiwe@yahoo.com \\ 4 ezutek@gmail.com
}

\begin{abstract}
This paper aims to solve the economic dispatch problem of the 28-bus Nigerian power system using genetic algorithm. The power flow solution of the network is first obtained using Newton-Raphson technique; the solution thus obtained is used to determine the loss coefficients of the network. For this study, a forecasted load demand of 2000MW will be considered, MATLAB's genetic algorithm optimization toolbox is used to obtain the optimum generation level of each unit. The optimal power output of each scheduled generating units was obtained after 200 iterations at a minimal generation cost of $\$ 136,370.205 / \mathrm{hr}$. A power loss of 11.32MW in the network was also obtained using Kron's loss formula.
\end{abstract}

Keywords: Genetic Algorithm, Economic Dispatch, loss coefficient, Optimization, Constraint

\section{INTRODUCTION}

In the Nigerian power system, with a large interconnected rapidly growing system, the Independent System Operators (ISO) and the unbundled Transmission Company of Nigeria (TCN) face different operational challenges including economic load dispatch of their generating units. The 28-bus model of the Nigerian grid used for this study is made up of 10 generator buses and 18 load buses with fifty-two (52) $330 \mathrm{kV}$ transmission lines distributed across the country interconnecting these various buses. Three (3) out of the ten (10) generator buses on the network are hydro, with Egbin a thermal power station of capacity $1100 \mathrm{MW}$ being the largest [1]. It can be seen that grid energy mix of the Nigerian power system is predominately hydrothermal in nature with most of the hydro resources (Kanji, Shiroro, Jebba) situated in the northern part of the country and the thermal units domicile in the south, due to the abundance of fossil fuel, i.e., natural gas in the south. In this paper, the solution to the economic dispatch problem of the Nigerian power system using genetic algorithm is discussed.

\footnotetext{
${ }^{*}$ Corresponding author, tel: +234-803-867- 8489
}

In the normal operating condition of a power system, the generation capacity should be greater than the total load demand plus losses thus giving room for various generation scheduling options. In a grid system or an interconnected power system, the sole aim of economic dispatch is to find the real and reactive power scheduling of each power plant in such a way as to minimize the cost of generating a specific forecasted load demand; it, therefore, implies that the generator's real and reactive power is allowed to vary within certain limits so as to meet a particular load demand at minimum cost, this is the economic load dispatch (ELD) problem [2]. The ELD problem is considered a large scale constrained nonlinear optimization problem [3]. For this economic dispatch study scheduled generators are represented by a cost function which relates the generation cost (in $\mathrm{A} / \mathrm{MW}$ ) to the power output (in MW) of each unit.

\section{LITERATURE REVIEW}

The economic dispatch problem has been previously solved using various conventional optimization techniques, generally referred to as traditional optimization techniques. These traditional optimization techniques are broadly divided into: 
calculus-based, exhaustive search and random search methods[4]. The calculus-based optimization technique is an analytical solution technique that requires the existence of the derivative of the objective function to be optimized, if the objective function is non-differentiable, which is mostly the case for most industrial application, this technique fails. Another shortfall of this technique is that it searches for local optimum, which limits its application if we do not know the neighborhood of the global optimum or if other local minima exist nearby [4]. The exhaustive search method tests every possible value of the objective function in search of an optimum point; its major limitation is that it requires a finite solution space. In practical problems, the search spaces are too vast to test every possibility one at a time and still have a chance of using the resulting information to some practical end [4]. Due to the shortcomings of the calculus-based and exhaustive search methods, the random search technique was introduced, as the name implies it performs a random search of the solution space. Using this technique leaves it to chance whether or not an optimum point will be found.

As the size of the system and the dimensions of the optimization problem increases, the use of traditional optimization techniques gradually becomes prohibitive; this is due to the large number of variables involved and the prolonged computation time. Thus the need for a faster and more efficient solution technique arose. With the introduction of the computers in the early 1950s, scientists began studying biological processes, writing programs that mimicked real-life biological processes. During the 1960s, three different implementations of this basic idea were developed in different places. In the USA, Fogel, Owens, and Walsh introduced "evolutionary programming" [5], while John Holland called his method a "genetic algorithm" $[6,7]$. Meanwhile, in Germany, Rechenberg and Schwefel develop their solution technique called "evolution strategies"[8]. For about 15 years these areas developed separately, but since the early 1990s, they have been viewed as different forms of one technology that has come to be known as "evolutionary computing" $[9,10]$. The development of Genetic Algorithms in Search, Optimization, and Machine Learning[4] was the final catalyst in setting off a sustained development of genetic algorithm theory and applications that are still growing rapidly up till date.

\section{THE ECONOMIC DISPATCH PROBLEM}

Economic dispatch is a short-term determination of the optimal power output or real power generation level of a number of generating units in an interconnected grid network in order to satisfy a particular forecasted load demand at minimum cost while meeting the various system and operational constraints. Some other constraints including voltage and system security constraints are assumed constant[11]. Consider a power network with $n$ number of generator plants and a given power demand of $\mathrm{PD}$, each $i^{\text {th }}$ plant has a cost-rate curve that gives the cost in $\mathrm{H} /$ hour as a function of its generation level $P_{i}$ (the 3phase power)[12], where the total power loss in the network is $\mathrm{PL}$.

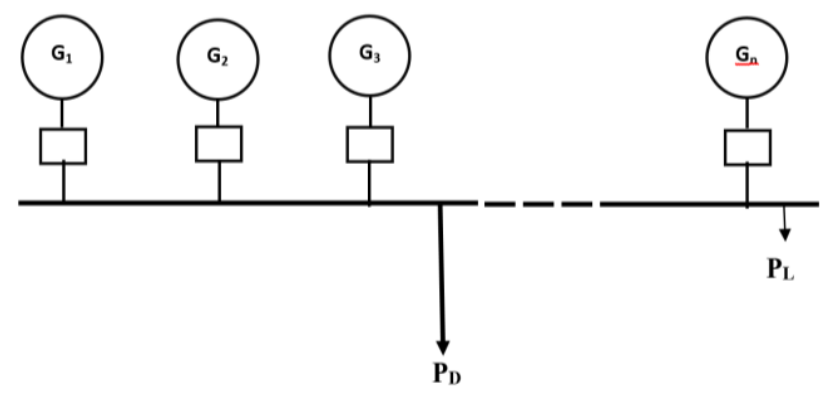

Fig. 1: Simplified power system with $n$ generating units.

The basic economics dispatch optimization problem can be written mathematically as[13]:

$$
\text { minimize } \sum_{i=1}^{n} C_{i}\left(P_{i}\right)
$$

Subject to the following set of constraints:

Power balance constraint, which can be expressed as equality constraint is:

$$
\sum_{i=1}^{n} P_{i}=P_{D}+P_{L}
$$

Inequality constraints of each generating unit's output power expressed as:

$$
P_{i}^{\min } \leq P_{i} \leq P_{i}^{\max }
$$

Where, $n=$ Total number of committed generators, $P_{i}=$ Real power output of the $i^{\text {th }}$ generator (in MW)., $P_{D}=$ Total Real Power demand (in MW). $P_{l}=$ Total system losses (in MW), $P_{i}^{\min }, P_{i}^{\max }$ represent the minimum and maximum limits (in MW) respectively of the $i^{\text {th }}$ generator and $C_{i}\left(P_{i}\right)$ is the cost of the generating $P_{i} \quad \mathrm{MW}$ by the $i^{\text {th }}$ generator. The generation cost of the $i^{t h}$ unit is expressed as a quadratic cost function of the form;

$$
C_{i}\left(P_{i}\right)=\propto_{i} P_{i}^{2}+\beta_{i} P_{i}+\gamma_{i}
$$


Where: $\propto_{i}-$ is the all efficiency factor; it is that part of the generation cost that depends on each unit's efficiency. $\beta_{i}$ - is the part of the cost that is directly proportional to the power output of the unit. For example, the fuel cost. $\gamma_{i}$ - is the constant term reflecting capital investment, salaries, interest rates, depreciation and other constant costs which are independent of generation.

To determine the total power loss, $P_{L}$ in the network in terms of the generator's real power output, the loss coefficient or B-coefficient method is used[11].

Using the B-coefficient method, the total system loss is expressed as:

$$
P_{l}=\left[P_{i}\right]^{T}[B]\left[P_{i}\right]+\left[B_{i 0}\right]\left[P_{i}\right]+B_{00}
$$

It can be further expressed in expanded form as:

$$
P_{l}=\sum_{i=1}^{n} \sum_{j=1}^{n} P_{i} B_{i j} P_{j}+\sum_{i=1}^{n} B_{i 0} P_{i}+B_{00}
$$

Where $B_{i j}, B_{i 0}$ and $B_{00}$ are the loss coefficient depending on the system topology and online parameters (reactors, capacitor banks and other compensating devices) [3].

\section{METHODOLOGY}

Genetic algorithms are guided random search and one of the most popular optimization techniques among evolutionary algorithms for multi-objective optimization problems[14]; when applied to optimization problems they search the solution space for values of the decision variables which optimizes the objective function. To evolve good solutions and to implement natural selection, there is need for a measure to distinguish good solutions from bad one[14]. This measure is usually the objective function (fitness function) which could be in the form of the mathematical model describing a system or a computer simulation. The basic principle behind this algorithm is that they create and maintain a population of potential solution represented by chromosomes.

A typically genetic algorithm is shown below:

\section{Start}

- Encode initial solutions in chromosomes.

- Generate a random population of $n$ chromosomes/individuals (suitable and possible solutions to the problem).

\section{While end condition not satisfied}

- Evaluate the fitness $f(x)$ of each chromosome/individual $\mathrm{x}$ in the population.
- Create a new population by repeating the following steps until the new population is complete.

- Select two parent chromosomes from a population according to their fitness (the better fitness, the higher chance to get selected).

- With a crossover probability, crossover the parents to form new offspring (children). If no crossover was performed, offspring is the exact copy of parents.

- With a mutation probability, mutate new offspring at each locus (position in chromosome).

- Place new offspring in the new population.

- Use the newly generated population for a further run of the algorithm.

Else

- If the end condition is satisfied, stop, and return the best solution in the current population.

\section{End}

The steps involved in solving the problem are discussed as follows:

1. The Bloss_calculator.m is executed to determine the loss coefficients of the network. Ifnetwon.m and bloss.m are used to determine the power flow solution of the network and the loss coefficients respective using the line and bus data as input. The loss coefficients obtained from Bloss_calculator are used as to determine the power loss in the network by applying equation 6 .

2. From equation 1 through 6 , it can be seen that the main decision variable of the economic dispatch problem is the real power output, $P_{i}$ of the various generators on the grid. To determine the optimal power output of each generator the power balance equality constraint of equation 2 is first collapsed into the objective function of equation 1 using the Penalty Factor method, the inequality constraint of equation 3 is taken care of by the genetic algorithm itself. The choice of chromosomes are such that the inequality constraint is not violated; therefore, the algorithm considers only $P_{i}$ values that fall within the maximum and minimum permissible power 
output of each unit. These steps now converts the constrained optimization problem into an unconstrained problem which is modelled and solved with a genetic algorithm.

Equation 2 can be rewritten as,

$$
\sum_{i=1}^{n} P_{i}-P_{D}-P_{L}=0
$$

Substituting for $P_{L}$ in equation 7 and adding equation to equation 1 yields an unconstrained objective function as given in equation 1.8 below.

$$
\begin{aligned}
\sum_{i=1}^{n} C_{i}\left(P_{i}\right)+10^{3} & \times a b s\left[\sum_{i=1}^{n} P_{i}-P_{D}\right. \\
& \left.-\sum_{i=1}^{n} \sum_{j=1}^{n} B_{i j} P_{i} P_{j}\right]
\end{aligned}
$$

Equation 8, the unconstrained objective function of the economic dispatch problem is scripted as the fitness function of the genetic algorithm and save to MATLAB's current directory as eldga.m.

3. Write a program that uses MATLAB's genetic algorithm optimization toolbox to minimize the fitness function eldga.m. This program called Project_GA.m takes the plant data and loss coefficients in the form of an excel file as input and applies the principles of evolution (selection, crossover, mutation and replacement) to continuously evolve a population of chromosomes (potential solutions) until the convergence criteria of the algorithm is satisfied. On convergence of the algorithm, the optimal power output for each plant is returned to MATLAB's command window. The parameters of the algorithm used in this program are defined as:

Population size $=5000$,

Maximum number of iterations $=500$,

Time limit $=200$ seconds and

Stall Time Limit $=50$.

Other parameters of the algorithm that are undefined by the programmer are automatically set to their default value by the program. The flowchart for the genetic algorithm solution of the economic dispatch problem of the Nigerian power system considering transmission losses is shown in Fig. 2.

\section{SYSTEM DATA}

The network parameters of the 28 bus $330 \mathrm{kV}$ Nigerian power system used are shown in Table 1-4. These parameters include line data, bus data, plant data, and generating plant characteristics. The oneline diagram of the Nigerian 28-bus network are shown in Fig. 3.

Table 1 below shows the bus name and bus numbers of the various buses shown on in Fig. 3, for this study, these bus numbers are unique to the buses and will be used to identify the buses within the MATLAB programs and the other input data.

Table 1: Buses Number and Name of the 28 Buses on the National Grid[15].

\begin{tabular}{llll}
\hline Bus No. & Bus Name & Bus No. & Bus Name \\
\hline 1 & Egbin & 15 & Aiyede \\
2 & Delta & 16 & Oshogbo \\
3 & Kanji & 17 & Benin \\
4 & Shiroro & 18 & Ajaokuta \\
5 & Sapele & 19 & Akangba \\
6 & Jebba G.S. & 20 & Ikeja West \\
7 & Afam & 21 & Onitsha \\
8 & AES & 22 & New Heaven \\
9 & Okpai & 23 & Alaoji \\
10 & Calabar & 24 & Aladia \\
11 & Gombe & 25 & Aja \\
12 & Jebba T.S. & 26 & Birnin Kebbi \\
13 & Jos & 27 & Kaduna \\
14 & Katampe & 28 & Kano \\
\hline
\end{tabular}

\subsection{Bus Data}

To determine the loss coefficients or the Bcoefficients $\left(B_{i j}, B_{0}\right.$ and $B_{00}$ ) of the system the bus data and line data are required as input to the Bloss_Calculator.m MATLAB program. Table 2 shows the bus data for the system; the first column contains the bus number, which corresponds to the numbering in Table 1 and Fig. 3. Column 2 contains the bus code used to identify the bus type where:

- Bus code 1: is the Slack bus,

- Bus code 2: is a Generator bus or a PV bus,

- Bus code 0: is a load bus or a PQ bus.

Columns 3 and 4 are the voltage magnitude (in p.u) and angle (in degrees) respectively. Columns 5 and 6 are the real power (in MW) and reactive power (in Mvar) consumed by the load connected to the bus. Columns 7 and 8 contain the generated real and reactive power respectively at the generator buses. Columns 9 and 10 shows the maximum and minimum reactive power output from the generators. Column 11 shows the reactive power injected into the system from compensating devices (capacitors and synchronous condensers) connected to the bus. 


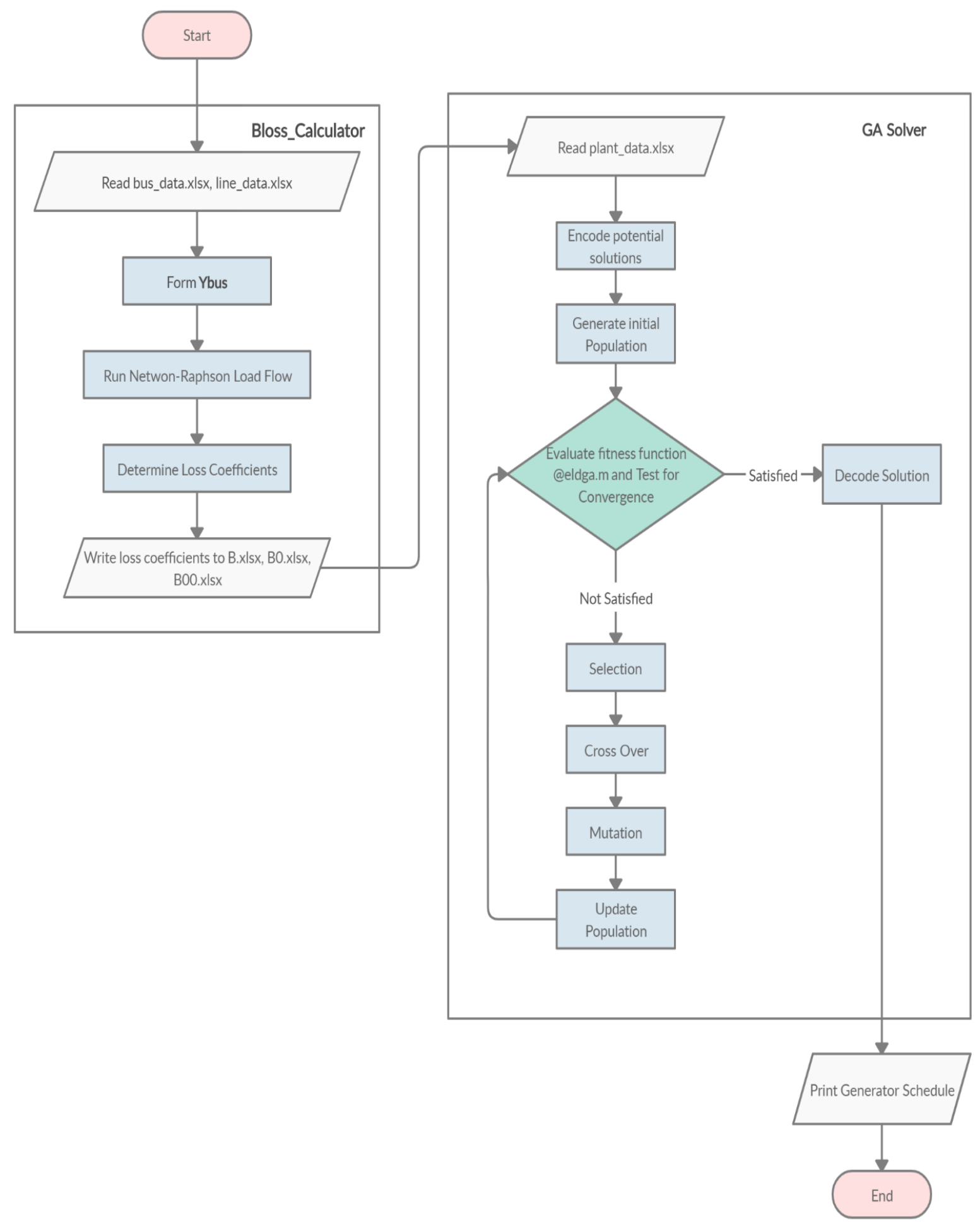

Fig. 2: Flowchart of the economic dispatch program. 


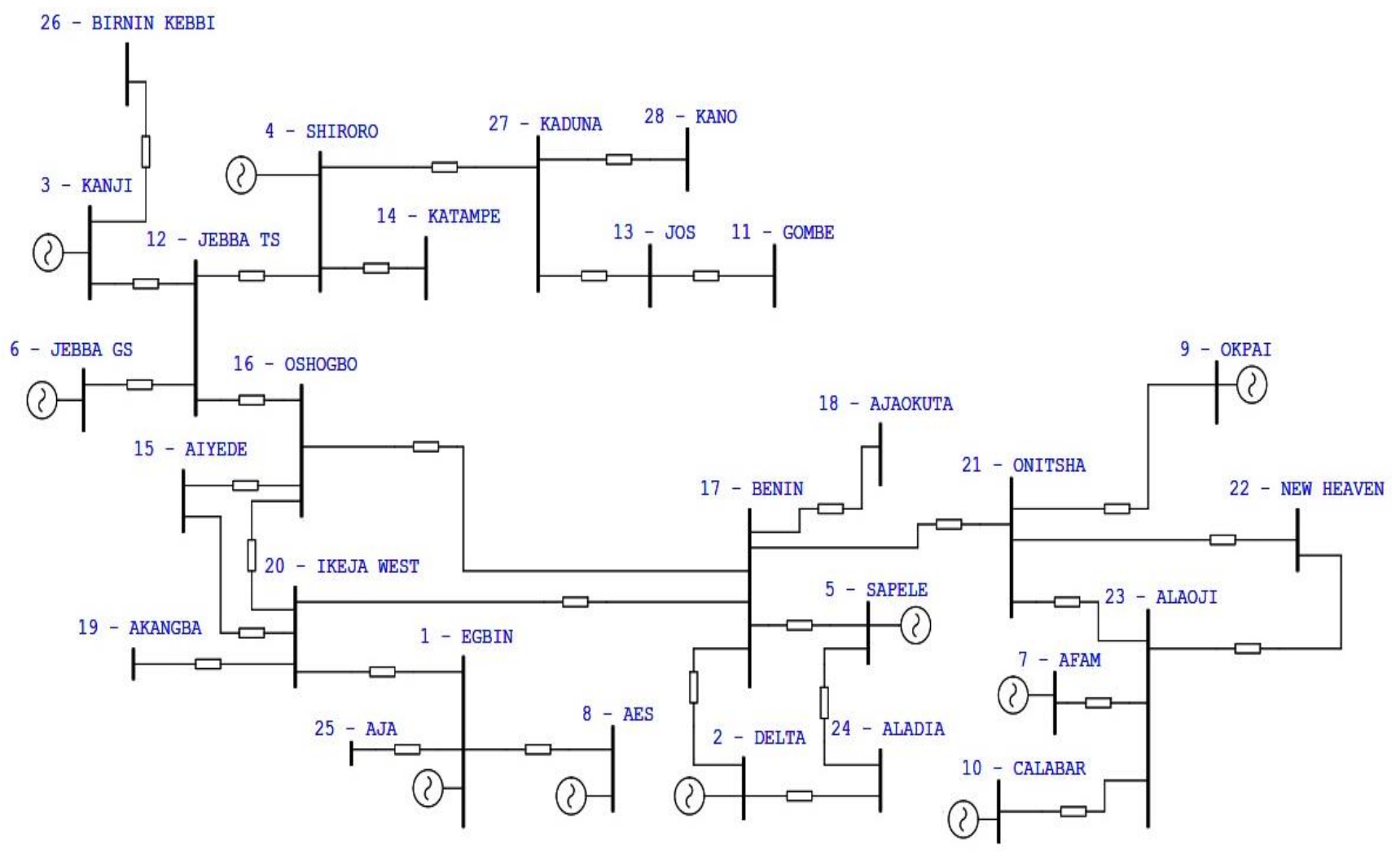

Fig. 3: One-line diagram of the existing 28 bus $330 \mathrm{kV}$ Nigerian transmission grid [15].

Table 2: Bus Data for 28 Bus 330KV Nigerian Grid[15].

\begin{tabular}{ccccccccccc}
\hline $\begin{array}{c}\text { Bus } \\
\text { No. }\end{array}$ & $\begin{array}{c}\text { Bus } \\
\text { Code }\end{array}$ & $\begin{array}{c}\text { Voltage } \\
\text { Mag.(in } \\
\text { p.u) }\end{array}$ & $\begin{array}{c}\text { Angle (in } \\
\text { Degree) }\end{array}$ & $\begin{array}{c}\text { Load } \\
\text { MW }\end{array}$ & $\begin{array}{c}\text { Load } \\
\text { Mvar }\end{array}$ & $\begin{array}{c}\text { Gen } \\
\text { MW }\end{array}$ & $\begin{array}{c}\text { Gen } \\
\text { Mvar }\end{array}$ & $\begin{array}{c}\text { Gen } \\
\text { Qmin }\end{array}$ & $\begin{array}{c}\text { Gen } \\
\text { Qmax }\end{array}$ & $\begin{array}{c}\text { Injected } \\
\text { Mvar }\end{array}$ \\
\hline 1 & 1 & 1 & 0 & 150 & 105.62 & 0 & 0 & -200 & 200 & 0 \\
2 & 2 & 1 & 0 & 200 & 300 & 882 & 0 & -300 & 320 & 0 \\
3 & 2 & 1 & 0 & 0 & 0 & 760 & 0 & -210 & 222 & 0 \\
4 & 2 & 1 & 0 & 0 & 0 & 600 & 0 & -120 & 140 & 0 \\
5 & 2 & 1 & 0 & 0 & 0 & 1020 & 0 & -250 & 260 & 0 \\
6 & 2 & 1 & 0 & 0 & 0 & 578 & 0 & -200 & 210 & 0 \\
7 & 2 & 1 & 0 & 0 & 0 & 931.6 & 0 & -290 & 300 & 0 \\
8 & 2 & 1 & 0 & 0 & 0 & 302 & 0 & -100 & 110 & 0 \\
9 & 2 & 1 & 0 & 0 & 0 & 480 & 0 & -200 & 210 & 0 \\
10 & 2 & 1 & 0 & 0 & 0 & 600 & 0 & -120 & 140 & 0 \\
11 & 0 & 1 & 0 & 0 & 0 & 0 & 0 & 0 & 0 & 0 \\
12 & 0 & 1 & 0 & 130 & 80 & 0 & 0 & 0 & 0 & 0 \\
13 & 0 & 1 & 0 & 220 & 154.8 & 0 & 0 & 0 & 0 & 0 \\
14 & 0 & 1 & 0 & 114 & 90 & 0 & 0 & 0 & 0 & 0 \\
15 & 0 & 1 & 0 & 110 & 80 & 0 & 0 & 0 & 0 & 0 \\
16 & 0 & 1 & 0 & 104 & 70 & 0 & 0 & 0 & 0 & 0 \\
17 & 0 & 1 & 0 & 36 & 25 & 0 & 0 & 0 & 0 & 0 \\
18 & 0 & 1 & 0 & 72 & 45 & 0 & 0 & 0 & 0 & 0 \\
19 & 0 & 1 & 0 & 136 & 84 & 0 & 0 & 0 & 0 & 0 \\
20 & 0 & 1 & 0 & 72 & 45 & 0 & 0 & 0 & 0 & 0 \\
21 & 0 & 1 & 0 & 39 & 27.8 & 0 & 0 & 0 & 0 & 0
\end{tabular}




\begin{tabular}{ccccccccccc}
\hline $\begin{array}{c}\text { Bus } \\
\text { No. }\end{array}$ & $\begin{array}{c}\text { Bus } \\
\text { Code }\end{array}$ & $\begin{array}{c}\text { Voltage } \\
\text { Mag.(in } \\
\text { p.u) }\end{array}$ & $\begin{array}{c}\text { Angle (in } \\
\text { Degree) }\end{array}$ & $\begin{array}{c}\text { Load } \\
\text { MW }\end{array}$ & $\begin{array}{c}\text { Load } \\
\text { Mvar }\end{array}$ & $\begin{array}{c}\text { Gen } \\
\text { MW }\end{array}$ & $\begin{array}{c}\text { Gen } \\
\text { Mvar }\end{array}$ & $\begin{array}{c}\text { Gen } \\
\text { Qmin }\end{array}$ & $\begin{array}{c}\text { Gen } \\
\text { Qmax }\end{array}$ & $\begin{array}{c}\text { Injected } \\
\text { Mvar }\end{array}$ \\
\hline 22 & 0 & 1 & 0 & 84 & 50 & 0 & 0 & 0 & 0 & 0 \\
23 & 0 & 1 & 0 & 146 & 84.5 & 0 & 0 & 0 & 0 & 0 \\
24 & 0 & 1 & 0 & 32 & 17.8 & 0 & 0 & 0 & 0 & 0 \\
25 & 0 & 1 & 0 & 110 & 80 & 0 & 0 & 0 & 0 & 0 \\
26 & 0 & 1 & 0 & 100 & 58.4 & 0 & 0 & 0 & 0 & 0 \\
27 & 0 & 1 & 0 & 80 & 49.6 & 0 & 0 & 0 & 0 & 0 \\
28 & 0 & 1 & 0 & 26 & 15.3 & 0 & 0 & 0 & 0 & 0 \\
\hline
\end{tabular}

\subsection{Line Data}

The line data for the 330kV transmission network is shown in Table 3, the per unit values in Table 3 are referred to MVA Base of 100MVA and Base Voltage of 330kV.

Table 3: Line Data for the 28 Bus 330KV Nigerian Grid[15].

\begin{tabular}{|c|c|c|c|c|c|}
\hline From Bus & To Bus & $\mathrm{R}$ (in p.u) & $X($ in $p . u)$ & $\mathrm{B} / 2$ (in p.u) & tap setting \\
\hline 1 & 8 & 0.0001 & 0.0004 & 0.0498 & 1 \\
\hline 1 & 20 & 0.0004 & 0.0029 & 0.0386 & 1 \\
\hline 1 & 25 & 0.0007 & 0.0057 & 0.0386 & 1 \\
\hline 3 & 17 & 0.0008 & 0.0063 & 0.1793 & 1 \\
\hline 2 & 24 & 0.0008 & 0.0063 & 0.1793 & 1 \\
\hline 3 & 26 & 0.0041 & 0.0304 & 0.9068 & 1 \\
\hline 3 & 12 & 0.001 & 0.0082 & 0.462 & 1 \\
\hline 4 & 27 & 0.0011 & 0.0097 & 0.273 & 1 \\
\hline 4 & 12 & 0.0022 & 0.0234 & 0.6953 & 1 \\
\hline 4 & 14 & 0.009 & 0.0067 & 0.8967 & 1 \\
\hline 5 & 17 & 0.0002 & 0.0015 & 0.468 & 1 \\
\hline 5 & 24 & 0.0008 & 0.0063 & 0.1793 & 1 \\
\hline 6 & 12 & 0.0001 & 0.0004 & 0.0498 & 1 \\
\hline 7 & 23 & 0.0015 & 0.0012 & 0.156 & 1 \\
\hline 9 & 21 & 0.0008 & 0.0063 & 0.1793 & 1 \\
\hline 10 & 23 & 0.0163 & 0.014 & 0.393 & 1 \\
\hline 11 & 13 & 0.0032 & 0.0027 & 0.7575 & 1 \\
\hline 12 & 16 & 0.0019 & 0.0159 & 0.4478 & 1 \\
\hline 13 & 27 & 0.0027 & 0.0202 & 0.6057 & 1 \\
\hline 15 & 16 & 0.0013 & 0.01 & 0.2999 & 1 \\
\hline 15 & 20 & 0.0016 & 0.0134 & 0.4029 & 1 \\
\hline 16 & 17 & 0.003 & 0.0254 & 0.7155 & 1 \\
\hline 16 & 20 & 0.0033 & 0.0227 & 0.741 & 1 \\
\hline 17 & 18 & 0.0023 & 0.0198 & 0.5559 & 1 \\
\hline 17 & 20 & 0.0034 & 0.0016 & 0.8508 & 1 \\
\hline 17 & 21 & 0.0016 & 0.0139 & 0.3905 & 1 \\
\hline 19 & 20 & 0.0007 & 0.0057 & 0.1928 & 1 \\
\hline 21 & 22 & 0.0011 & 0.0097 & 0.2738 & 1 \\
\hline 21 & 23 & 0.0163 & 0.014 & 0.393 & 1 \\
\hline 22 & 23 & 0.0023 & 0.0171 & 0.6953 & 1 \\
\hline 27 & 28 & 0.0027 & 0.0202 & 0.6057 & 1 \\
\hline
\end{tabular}




\subsection{Plant Data}

The plant data of interest are: $\gamma, \beta, a$, maximum and minimum real power output, these can be obtained from the generating stations logs or from the manufacturers data sheet as shown in Table 4.

The fuel cost factor, $\beta$ in the cost equation of the hydro plants is approximated to zero as the fuel cost of hydro stations is negligible.

\section{RESULTS AND DISCUSSIONS}

The Bloss_calculator is first executed to determine the loss coefficients $\mathrm{B}, \mathrm{B} 0$ and $\mathrm{B} 00$ of the network.
The loss coefficient obtained for the network with line_data.xlsx and bus_data.xlsx is shown below.

These loss coefficients obtained here are used to evaluate the power loss in the network for this particular network configuration and load demand using the Kron's loss formula of equation 6.

Next, the economic dispatch program, Project_GA.m is executed. This program prompts the user to enter power demand, $\mathrm{P}_{\mathrm{D}}$, which in this study is $2000 \mathrm{MW}$. On convergence of the genetic algorithm, the following optimum generator schedule was obtained.

Table 4: Available Generating Plant Characteristics[1].

\begin{tabular}{ccccccc}
\hline Bus No. & Bus Name & $Y$ & $\beta$ & a & P_Min & P_Max \\
\hline 1. & Egbin & 0.031 & 13.1 & 12787 & 275 & 1100 \\
2. & Delta & 1.2 & 6.13 & 525.74 & 75 & 300 \\
3. & Sapele & 0.13 & 7.84 & 6929 & 137.5 & 550 \\
4. & Afam & 0.0092 & 56 & 1998 & 135 & 540 \\
5. & Kanji & 0.05 & 0 & 15200 & 50 & 500 \\
6. & Shiroro & 0.027 & 0 & 8200 & 50 & 450 \\
7. & Jebba & 0.07 & 0 & 2552 & 100 & 400 \\
8. & AES & 0.453 & 22 & 3886 & 135 & 540 \\
9. & Okapi & 1.13 & 10.3 & 480.58 & 150 & 600 \\
10. & Calabar & 0.05 & 38.7 & 2732 & 100 & 350 \\
\hline
\end{tabular}

The Loss coefficients of the Network are:

$\mathrm{B}=$

Columns 1 through 7

$\begin{array}{rrrrrrr}0.0029 & -0.0005 & -0.0003 & -0.0013 & -0.0002 & -0.0003 & -0.0013 \\ -0.0005 & 0.0024 & 0.0004 & -0.0009 & 0.0009 & -0.0001 & -0.0001 \\ -0.0003 & 0.0004 & 0.0012 & -0.0001 & 0.0005 & 0.0006 & -0.0002 \\ -0.0013 & -0.0009 & -0.0001 & 0.0039 & -0.0005 & 0.0006 & -0.0019 \\ -0.0002 & 0.0009 & 0.0005 & -0.0005 & 0.0010 & 0.0002 & -0.0000 \\ -0.0003 & -0.0001 & 0.0006 & 0.0006 & 0.0002 & 0.0011 & -0.0007 \\ -0.0013 & -0.0001 & -0.0002 & -0.0019 & -0.0000 & -0.0007 & 0.0117 \\ 0.0024 & -0.0004 & -0.0003 & -0.0011 & -0.0002 & -0.0002 & -0.0011 \\ -0.0005 & 0.0006 & 0.0005 & -0.0008 & 0.0007 & 0.0000 & 0.0020 \\ -0.0013 & -0.0002 & -0.0003 & -0.0019 & -0.0001 & -0.0008 & 0.0099\end{array}$


Columns 8 through 10

$\begin{array}{rrr}0.0024 & -0.0005 & -0.0013 \\ -0.0004 & 0.0006 & -0.0002 \\ -0.0003 & 0.0005 & -0.0003 \\ -0.0011 & -0.0008 & -0.0019 \\ -0.0002 & 0.0007 & -0.0001 \\ -0.0002 & 0.0000 & -0.0008 \\ -0.0011 & 0.0020 & 0.0099 \\ 0.0024 & -0.0005 & -0.0010 \\ -0.0005 & 0.0034 & 0.0017 \\ -0.0010 & 0.0017 & 0.0273\end{array}$

$\mathrm{B} 0=$

Columns 1 through 7

$\begin{array}{lllllll}0.0177 & 0.0084 & -0.0045 & -0.0155 & 0.0010 & -0.0032 & -0.0291\end{array}$

Columns 8 through 10

$0.0122-0.0091 \quad-0.0396$

$\mathrm{B} 00=$

0.1138

Plant data must have 5 columns: 1.a (Naira/MW^2) 2. b Naira/MW

3. c () 4.lower limit(in MW) 5.Upper limit(in MW)

The Maximum System generating Capacity is: $5330.00 \mathrm{MW}$

The Minimum System generating Capacity is: $1207.50 \mathrm{MW}$

$\mathrm{N} / \mathrm{B}$ : The power Demand for the committed units must be in the range $1207.50 \mathrm{MW}$ to $5330.00 \mathrm{MW}$

Optimization terminated: average change in the fitness value less than options.TolFun.

Elapsed time is 173.879729 seconds.

For a Power Demand of 2000.000000MW

The optimal power outputs of generator $\mathrm{G} 1=277.46 \mathrm{MW}$

The optimal power outputs of generator G2 $=75.09 \mathrm{MW}$

The optimal power outputs of generator G3 $=291.63 \mathrm{MW}$

The optimal power outputs of generator G4 $=450.00 \mathrm{MW}$

The optimal power outputs of generator G5 $=138.17 \mathrm{MW}$

The optimal power outputs of generator G6 $=256.17 \mathrm{MW}$

The optimal power outputs of generator G7 $=136.89 \mathrm{MW}$

The optimal power outputs of generator G8 $=135.56 \mathrm{MW}$

The optimal power outputs of generator G9 $=150.36 \mathrm{MW}$

The optimal power outputs of generator $\mathrm{G} 10=100.00 \mathrm{MW}$

The Total Power loss in the network is $11.326364 \mathrm{MW}$

The cost of generating this power is $136370.205501 \mathrm{Naira} / \mathrm{hr}$ 


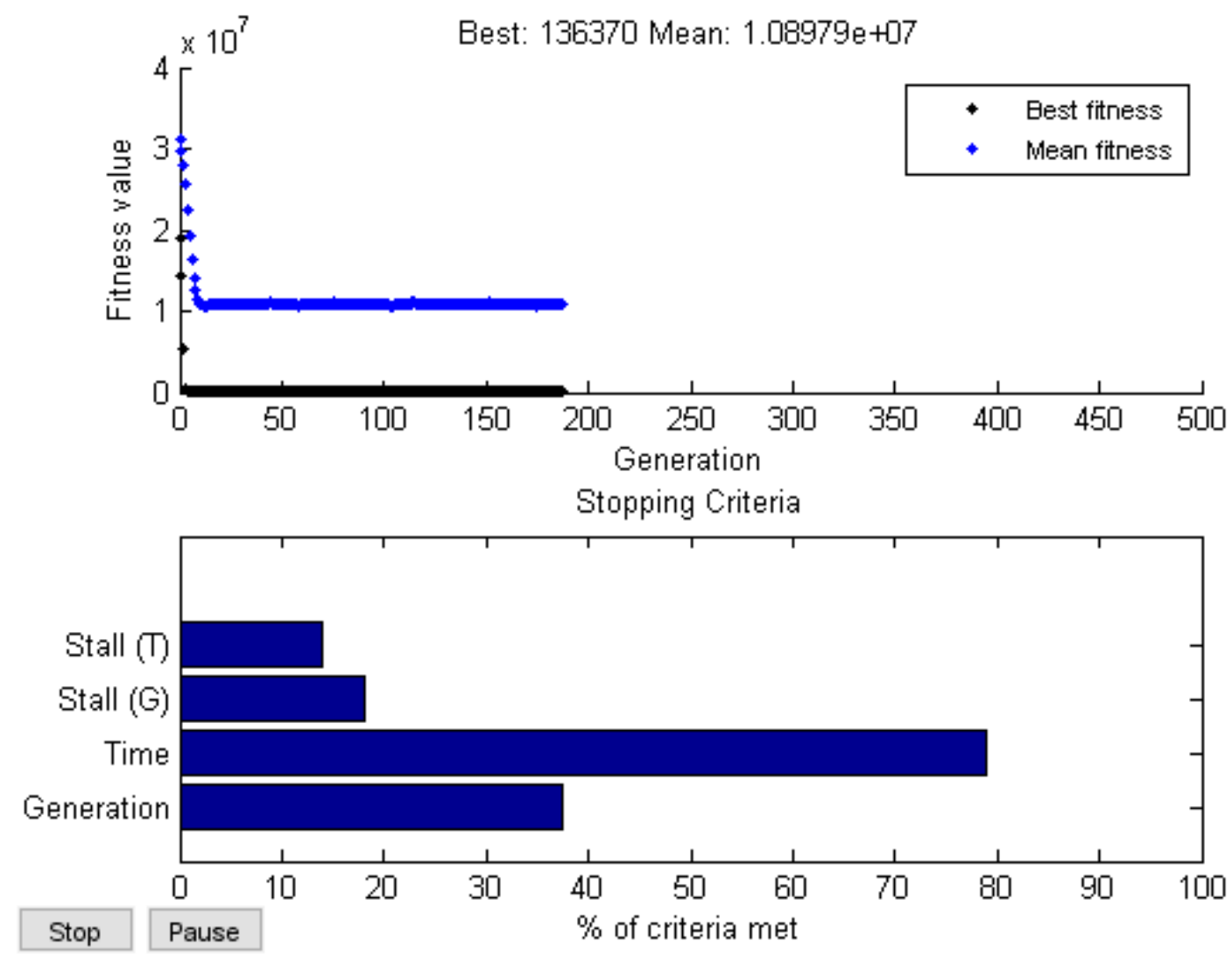

Fig. 4: Plot of the best individual and stop criteria for power demand of 2000MW.

Shown in Fig. 4 are two plots: a plot of "Fitness values vs. Generation" and a plot of "Stopping Criteria", these plots show the performance of the algorithm form initialization to convergence graphically. The plot of the "Fitness Value vs. Generation" as the name implies plots the mean fitness value of the chromosomes (which represents the average value of the encoded solution) and the best-fit individual (minimum generation cost) of the current generation against the generation (number of iterations). From this plot, we can deduce the following:

- The mean fitness value started up high at about $3.2 \times 10^{7}$ when the algorithm was first initialized, as the algorithm progressed, the mean fitness value of the population rapidly dropped within the first 10 iterations of the $\mathrm{GA}$, after which there was a relatively slower drop to about $1.1 \times 10^{7}$ after the next 5 generations.

- From the $15^{\text {th }}$ generation, the mean fitness value remained relatively unchanged until the GA converged.

- The best-fit individual (minimum generation cost) of each generation, which represent the optimum solution which is sought is also shown for each generation (iteration); it can be deduced from the plot that the change in fitness value of the best-fit individual relatively remained stable after the first few iterations.

- The number of iterations the GA has performed so far; this, in turn, informs the user of how slow or fast the GA is progressing towards an optimal point. If the GA is too slow, a reduction in population size of each generation can be considered to reduce computation time, and if on the other hand, the GA is too fast, it may have converged prematurely, in which case the population size should be increased.

The second plot in Fig. 4 gives information on how close the GA approaches convergence based on some preset stop criteria; it graphically shows what percentage of the predefined stop criteria has been met so far. For this project the stop criteria were defined as: Maximum number of iterations $=500$, Time limit $=200$ secs, Stall Time Limit $=50$ and TolFun $=1 \times 10^{-200}$. The maximum number of iterations sets a limit to the number of times the GA iterates, and it stops the process if the set value for the maximum number of iteration (which in this case is 500) is 
reached. The time limit is another criteria on which the GA can converge; it stops the GA process if the time limit set by the user has been reached, this prevents the algorithm from iterating past a certain time limit. The time limit used in this study is 200 secs, the choice of this value depends on the size of the optimization problem, the speed of the computing machine, and the population size. The stall time limit sets a limit on how long the algorithm runs if there is no perceptible change in fitness value of the best-fit individual of the population while TolFun defines the sensitivity of the algorithm to a change in the fitness function, it is the smallest perceptible change in the value of the fitness function. This information available from Fig. 4 provides a visual guide to the user from start to finish of the iteration process.

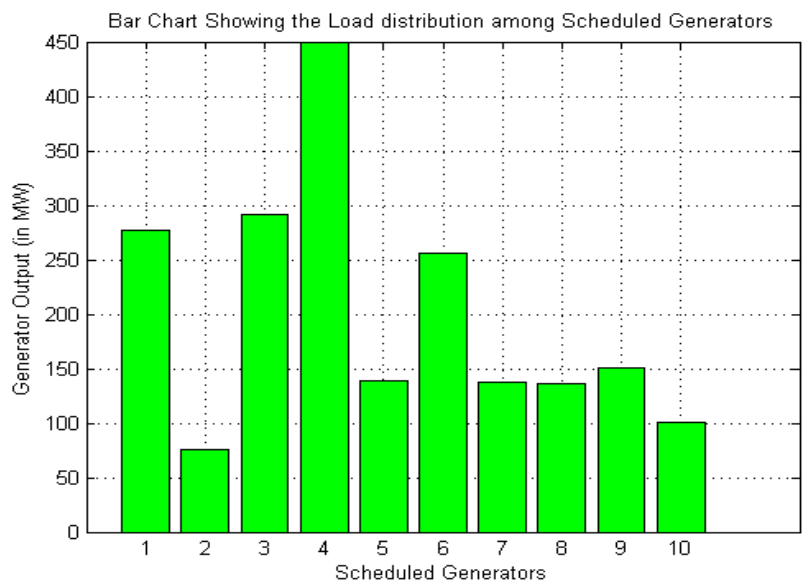

Fig. 5: A bar chart showing graphically how a load of 2000MW will be optimally distributed among the various online generators.

The output of the MATLAB program Project_GA.m shown above in Fig. 5 is the optimal generator schedule for the ten (10) generators buses on the network.

\section{CONCLUSION}

By critically analysing the result of the economic dispatch program, the power system operator can quickly draw the following inferences:

- The optimal generating cost for this load demand, $P_{D}$ of 2000MW and scheduled generators is $136,370.205 / \mathrm{hr}$.

- The power loss, PL of the system for this network configuration and load demand is 11.326MW.

- From Fig. 5, it is clearly observed that bulk of the load is allotted to the hydro generating stations; Gen3 (Kanji hydro station), Gen 4 (Shiroro hydro station) and Gen 6(Jebba hydro station) in addition to the thermal power plant Gen1 (Egbin); this is due to the low generation cost and high efficiency of these power stations. These high efficiency and low generating cost units are called Baseload units.

- It can also be inferred from Fig. 5 that Gen2 (Delta thermal power station) is the most uneconomical and cost-inefficient unit in the network; therefore its output has been pegged at the barest minimum. Units like this high cost of generation are called peak-load unit and are running at maximum capacity only when other generation resources have been exhausted.

The genetic algorithm solution used in this paper can be readily applied to any power system network with any number of buses. If accurate data is available and used, accurate results are guaranteed. Most times the accuracy of the result obtained from the Project_GA.m strictly depends on the accuracy and resolution of the available data and not on the genetic algorithm itself.

\section{REFERENCES}

[1] Olakunle, A.O and Folly, K.A, "Economic Load Dispatch of Power System Using Genetic Algorithm with Valve Point effect", International Conference in Swarm Intelligence, pp. 276-284, 2015.

[2] Saadat, H. "Power System Analysis," New York: McGraw-Hill, 1999, pp. 189-309.

[3] Al-Shetwi, A.Q and Alomoush M.I, "A New Approach to the Solution of Economic Dispatch Using Genetic Algorithm," Journal of Engineering and Technology, vol. 7, no. 1, pp. 40-48, 2016.

[4] Goldberg D. "Genetic algorithms in search, optimization, and machine learning," In Choice Reviews Online, vol. 27, no. 02, Boston: Kluwer Academic Publishers, 2013, pp. 27-0936-27-0936.

[5] Fogel, L.J, Owens, A.J and Walsh, M.J "Artificial intelligence through a simulation of evolution," in Evolutionary Computation: The Fossil Record, Washington DC: Spartan, 1965, pp. 131-156.

[6] De Jong, K.A. "Genetic Algorithms are not Function Optimizers," Science (80-. )., pp. 5-18.

[7] Holland, J. "Genetic Algorithms and the Optimal Allocation of Trials," SIAM J. Comput., vol. 2, no. 2, pp. 88-105, Jun. 1973.

[8] Rechenberg, I. "Optimierung technischer Systeme nach Prinzipien der biologischen Evolution", Stuttgart: Frommann-Holzboog-Verlag, 1973.

Vol. 38, No. 4, October 2019 
[9] Bäck, T. "Evolutionary Algorithms in Theory and Practice: Evolution Strategies, Evolutionary Programming, Genetic Algorithms". New York, NY, USA: Oxford University Press, Inc., 1996.

[10] Bäck, T., Fogel, D.B and Michalewicz, Z. "Evolutionary computation 2: Advanced algorithms and operators", Philadelphia: Institute of Physics Publishing, 2000.

[11] Zaraki, A.T.M and Mohd, F. "Implementing Particle Swarm Optimization to Solve Economic Load Dispatch Problem," International Conference on Soft Comput. Pattern Recognition., pp. 60-65, 2009.

[12] Alayande, A.S, Olowolaju, J.T and Okakwu, I.K. "Solving Optimal Generation Dispatch Problem in Power Networks Through PSO and Lambda Iteration Techniques," Nigerian Journal of
Technology, vol. 38, no. 1, pp. 165-176, 2019.

[13] Wood, Aand Wollenberg, B. "Power Generation, Operation and Control", New York: John Wiley \& Sons, 1984.

[14] Jang, E.Y, "Performance of Optimization for short Reference Differential Chaos Shift Keying Scheme", Korean Institute of Electronic Communication Science, vol. 14, No. 03, PP. 543460, 1992.

[15] I. O. Akwukwaegbu, O. C. Nosiri, C. K. Agubor, and M. Olubiwe, "Comparative Power Flow Analysis of 28 and 52 Buses for 330KV Power Grid Networks in Nigeria Using Newton-Raphson Method," International. Journal of Recent Eng. Research and Dev., vol. 02, no. 05, pp. 01-23, 2017. 